\title{
A metapopulation model to simulate West Nile virus circulation in Western Africa, Southern Europe and the Mediterranean basin
}

\author{
Benoit Durand $^{1 *}$, Gilles Balança ${ }^{2}$, Thierry Baldet ${ }^{3}$, Véronique Chevalier ${ }^{2}$ \\ ${ }^{1}$ Afssa LERPAZ, 23 avenue du Général de Gaulle, 94706 Maisons-Alfort Cedex, France \\ ${ }^{2}$ CIRAD UR AGIRs Campus International de Baillarguet, TA 30/G, 34398 Montpellier, France \\ ${ }^{3}$ IRD-CREC-CIRAD, 08 BP 841 Cotonou, Benin
}

(Received 3 July 2009; accepted 13 January 2010)

\begin{abstract}
In Europe, virological and epidemiological data collected in wild birds and horses suggest that a recurrent circulation of West Nile virus (WNV) could exist in some areas. Whether this circulation is permanent (due to overwintering mechanisms) or not remains unknown. The current conception of WNV epidemiology suggests that it is not: this conception combines an enzootic WNV circulation in tropical Africa with seasonal introductions of the virus in Europe by migratory birds. The objectives of this work were to (i) model this conception of WNV global circulation; and (ii) evaluate whether the model could reproduce data and patterns observed in Europe and Africa in vectors, horses, and birds. The model was calibrated using published seroprevalence data obtained from African (Senegal) and European (Spain) wild birds, and validated using independent, published data: seroprevalence rates in migratory and resident wild birds, minimal infection rates in vectors, as well as seroprevalence and incidence rates in horses. According to this model, overwintering mechanisms are not needed to reproduce the observed data. However, the existence of such mechanisms cannot be ruled out.
\end{abstract}

West Nile virus / model / Europe / Africa / dissemination

\section{INTRODUCTION}

West Nile fever (WNF) is an emerging arbovirosis caused by the West Nile virus (WNV) (Flavivirus, Flaviviridae). The basic transmission cycle involves wild and domestic birds as main hosts and mosquitoes, mainly from the Culex genus, as vectors. This basic cycle may be amplified under favourable ecological conditions and lead to human and horse infections. The latter two are considered to be dead-end hosts [9]. The disease is presumed to be endemic in Africa, Europe, and Asia. Introduced in New York City in 1999, WNV

\footnotetext{
"Corresponding author: b.durand@afssa.fr
}

quickly spread through North, Central and South America. The epidemiological characteristics of this particular epidemic appear quite different from the situation in Southern Europe and the Mediterranean basin [76]. In this region, the virus may be introduced periodically into Europe from African endemic areas by migratory birds [14].

Tsai [71] proposed two epidemiological cycles that could operate more or less independently in both Africa and Europe. The first is a sylvatic cycle involving non-synanthropic bird species and ornithophilic mosquitoes. The second is an urban cycle involving synanthropic bird species and opportunistic mosquitoes. According to Tsai [71], migratory birds arriving 
in Europe from Africa introduce the virus into the sylvatic cycle. Then, WNV could be introduced in a peridomestic cycle, involving peridomestic birds such as magpies and opportunistic mosquitoes; and occasionally into an urban cycle, where its amplification would cause human and equine epidemics.

However, virological and epidemiological arguments suggest that enzootic cycles could also be maintained in some specific locations north of the Sahara. Viral phylogenetic studies group circulating WNV isolates into two lineages, I and II [57]. Strains from both lineages circulate in tropical Africa. Therefore, strains from both lineages thus could be introduced into Europe by migratory birds. However, all European isolates belong to lineage I [57] with the sole exception of lineage II strains recently isolated from migratory birds and sheep in Hungary $[5,24,42]$. All of the strains responsible for recent outbreaks in the Mediterranean basin are genetically close and may have evolved from those isolated in the 1960s in the same region [57]. Thus, some WNV strains may have been circulating in sylvatic cycles in Europe since the 1960s. Indeed, in several European countries, serological studies have shown a low-level circulation of WNV: Czech Republic [35], Poland [41], Romania [67], France [36, 37] and Spain [46]. In these studies, WNV circulation was demonstrated by seropositive results in resident birds [36, 41, 67] and/or in hatch-year migratory birds captured in summer [35, 37, 46]. In specific areas (e.g. Camargue, France), follow-up of wild avifauna has shown a low but regular WNV circulation [6]. In addition, a seroprevalence study conducted on horses in France (2003) showed prevalence rates increasing with age. This suggested a recurrent WNV circulation in specific places of the study zone, located near protected bird conservation areas [23].

When studying WNV circulation patterns in Southern Europe and the Mediterranean basin, it is thus difficult to disentangle the roles of the African and European study areas, the respective importance of resident bird populations, and the importance of the migrant populations that link both continents. In particular, while epidemiological studies clearly demonstrate recurrent WNV circulation in some European areas, they have not determined whether the virus is regularly re-introduced from Africa or if it circulates permanently in Europe. The first hypothesis does not account for the genetic similarity of European isolates. Meanwhile, the second hypothesis implies either a continuous WNV circulation in specific areas of Mediterranean countries where mosquitoes would remain active yearlong, or the existence of virus overwintering mechanisms, such as transovarial WNV transmission in mosquitoes [58], the existence of other competent vectors (e.g. ticks) that could remain active yearlong $[1,55]$, overwintering of infected females, or a direct virus transmission between birds [3, 33, 43].

The goal of the study described in this paper was to model WNV circulation between Southern Europe and West Africa, with the assumption that there is no WNV overwintering mechanism in Europe. We then evaluated whether the model made it possible to explain independent serological data obtained from wild birds trapped in Africa and Europe.

\section{MATERIALS AND METHODS}

\subsection{Model}

The model is a deterministic discrete time metapopulation model with a daily time step. The epidemiological system is represented by a set of host populations that share during their annual life cycle a set of locations where vector populations live. Some of the host populations are migratory and move between locations during the year. Incidental hosts (sentinel chickens and horses) are also living in each location and are exposed to infectious bites. For each host population, state variables are the proportions of birds in each age class (nestlings, juveniles, and reproductive adults) and health state (susceptible, viraemic, and immune). State variables describing vector populations correspond to the proportions of mosquitoes in each of the three possible mosquito health states: susceptible, latent (during the extrinsic incubation period), and infectious (when biting, the vector will transmit the virus to the host). Equations describing bird and vector population dynamics are provided in Supplementary data available on line at www.vetres.org. The infection dynamics coupling bird and vector populations is described in Figure 1. 


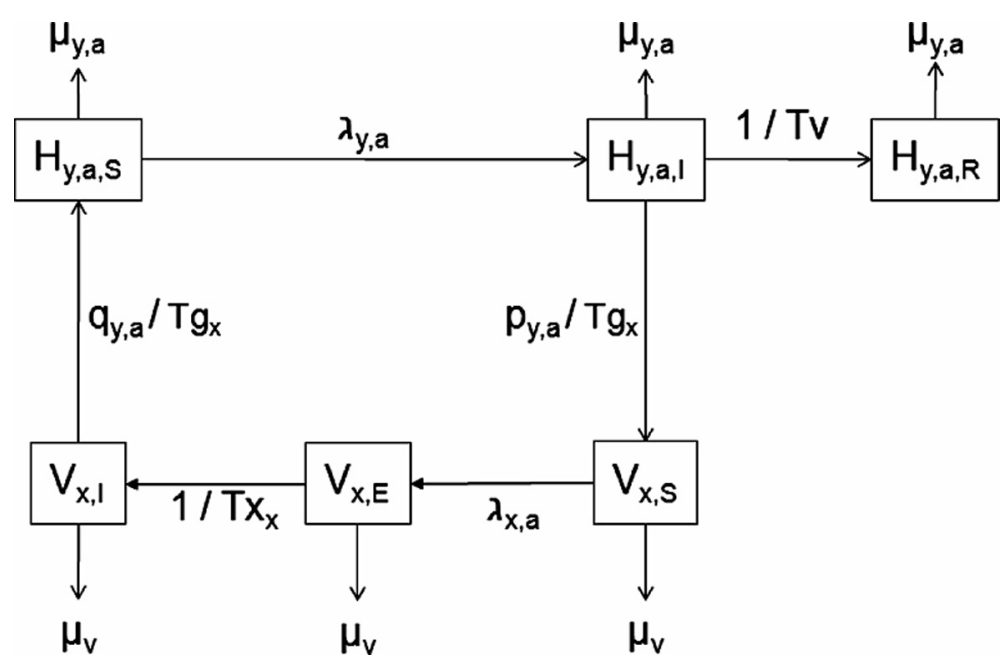

Figure 1. Structure of the metapopulation model. $H_{y, a, z}$ : proportion of birds in age class $a$, health state $z$ of population $y ; V_{x, z}$ : proportion of vectors living at location $x$ that have the health state $z ; \mu_{y, a}$ : daily mortality rate of birds in age class $a$ of population $y ; \mu_{v}$ : vector daily mortality rate; $\lambda_{y, a}$ : force of infection for hosts in age class $a$ of population $y$; $T v$ : duration of viraemia in hosts; $T g_{x}$ : duration of gonotrophic cycle in vectors living at location $x$; $T x_{x}$ : duration of the extrinsic incubation period in vectors living at location incubation period in vectors living at location $x ; q_{y, a}$ : proportion of bites that occur on birds of population $y$ and age class $a$; and $p_{y, a}$ : proportion of viraemic birds in population $y$ and age class $a$.

The equations are provided in Supplementary data on line.

\subsection{Parameterisation}

\subsubsection{Population dynamic parameters}

Three locations were considered: a wet African area, a dry African area, and a European Mediterranean area. Three resident bird populations live in these areas, as do three vector populations. Two migratory bird populations link the three areas: long distance migrants (wet African area-European area) and short distance migrants (wet African area-dry African area).

Resident and migratory bird populations represent passerines. Population dynamic parameters given in Table I were fixed according to published data. Populations were assumed to be demographically stable. The daily per-capita hatch rate as well as the juvenile recruitment rate was computed to ensure this stability. Migrations are represented as instantaneous changes of bird population locations. Migration dates and demographic importance of bird populations (when they share the same area) are given in Table I.
The vector populations are represented by Culex pipiens in the European area and Culex univittatus in the two African areas. Indeed these two mosquito species are part of the main WNV vector species in Europe and Africa [34]. Population dynamic parameters were fixed based on literature data (Tab. II). Seasonal abundance variations are represented by a simple site-specific rectangular-shaped dynamic, with a maximal value (relative abundance of $100 \%$ ) during a specific period of the year, and a base abundance level (relative abundance $<100 \%$ ) during the rest of the year. In African areas, maximal abundance period was assumed to coincide with the rainy season (mid-July to mid-October). During the dry season, this activity was null in the dry area. Due to irrigation, a base level of vector activity remained in the wet area. The corresponding relative abundance was fixed at $20 \%$ by entomologists based on their knowledge of the area ${ }^{1}$. In the Southern European area, vectors were assumed to be active only between mid-April and mid-October (Tab. II).

\footnotetext{
${ }^{1}$ Baldet T., Mondet B., personal communication.
} 
Table I. Parameter definitions and values: hosts.

\begin{tabular}{lcc}
\hline Parameter & Value & References \\
\hline Duration of fledging period & 13 days & {$[17-19]$} \\
Percentage of young fledged & 0.65 & {$[69]$} \\
Juvenile survival rate & 0.35 & {$[17-19]$} \\
Adult annual survival rate & 0.45 & {$[50]$} \\
Sexual maturity & 1 year & {$[17-19]$} \\
Migration: presence on breeding sites & & \\
Short distance migrants & 15 June-15 Oct \\
Long distance migrants & 15 Apr-15 Oct & {$[53,54]$} \\
Hatch period & & {$[17-19]$} \\
Wet African area residents & Permanent & {$[53,54]$} \\
Dry African area residents & 15 July-15 Oct \\
European area residents & 15 Apr-30 July & {$[53,54]$} \\
Short distance migrants & $15 \mathrm{July}-15$ Oct & {$[17-19]$} \\
Long distance migrants & & {$[53,54]$} \\
Demographic weights & & {$[17-19]$} \\
Wet African area, wintering period & $25 \%$ & \\
$\quad$ Resident population & $75 \%(10 \%, 90 \%)$ & {$[53,54]$} \\
$\quad$ Migrants (short, long distance) & & {$[53,54]$} \\
Dry African area, nesting period & $25 \%$ & {$[53,54]$} \\
$\quad$ Resident population & $75 \%$ & {$[53,54]$} \\
$\quad$ Short distance migrants & & {$[17-19]$} \\
European area, nesting period & $75 \%$ & {$[17-19]$} \\
$\quad$ Resident population & $25 \%$ & {$[43]$} \\
Long distance migrants & 5 days & \\
Duration of viraemia & &
\end{tabular}

\subsubsection{Calibration of the infection dynamic parameters}

Tables I and II give the duration of the extrinsic incubation period in vectors and that of infective viraemia in birds. Both were fixed based on literature data. Infective vectors were assumed to remain infective until they die [16]. Other infection dynamic parameters (age-specific bite relative risk and sitespecific vector-host ratios) were estimated using published seroprevalence data (Tab. III) obtained in wild birds $[15,46]$. These data were collected in a wet African area (the Senegal river Delta, Senegal) [15], in a dry African area (Ferlo, Senegal) [15], and in a Southern European area (Seville area, Spain) [46]. Two age classes were considered for the variations of the bite relative risk: nestlings, chosen as the reference class, and flying individuals (juveniles and adults). Juvenile and adult bite relative risk (denoted $R R$ ), as well as site-specific vector-host ratios (denoted $K_{x}$ for area $x$ ) were estimated minimising the log-likelihood of the above data (numbers of tested and seropositive birds) (Tab. III). These data were assumed to result from a binomial process, the epidemiological system being at its equilibrium state and reproducing each year the same dynamic, so-called limit cycle. To obtain a numerical estimate of this state, the following procedure was applied: bird and vector populations were initially fully susceptible, except for the wet African area, where infection was seeded in the vector population $(0.1 \%$ of vectors in the I state). The model was then run year by year. Yearly absolute variations of state variables were computed each January 1st. The simulation process was stopped when these variations became negligible $\left(<10^{-15}\right.$ for each of the age- and health-state specific state variables describing bird populations). Using the resulting state as the initial situation, a one-year dynamic was finally computed and considered a numeric approximation of the limit cycle. Confidence intervals of parameter estimates were computed from the Hessian matrix. The core of the model was programmed using the $\mathrm{C}$ language. It was embedded in the $\mathrm{R}$ environment [64] with which 
Table II. Parameter definitions and values: vectors.

\begin{tabular}{|c|c|c|}
\hline Parameter & Value & References \\
\hline \multicolumn{3}{|l|}{ Average vectors lifetime } \\
\hline Africa & 8 days & {$[30]$} \\
\hline Europe & 16 days & [31] \\
\hline \multicolumn{3}{|l|}{ Duration of extrinsic incubation period } \\
\hline Africa & 10 days & {$[16,39,40]$} \\
\hline Europe & 14 days & {$[21,25,38,70]$} \\
\hline \multicolumn{3}{|l|}{ Duration of the gonotrophic cycle } \\
\hline Africa & 3 days & {$[30]$} \\
\hline Europe & 4 days & [31] \\
\hline \multicolumn{3}{|l|}{ Activity period and relative abundance } \\
\hline \multicolumn{3}{|l|}{ Africa } \\
\hline Period with maximal abundance & 15 July-15 Oct & {$[51]$} \\
\hline \multicolumn{3}{|l|}{ Relative abundance } \\
\hline During this period & $100 \%$ & Reference value \\
\hline \multicolumn{3}{|l|}{ During the rest of the year } \\
\hline Wet area & $20 \%$ & Expert opinion \\
\hline Dry area & $0 \%$ & Expert opinion \\
\hline \multicolumn{3}{|l|}{ Europe } \\
\hline Period with maximal abundance & 15 Apr-15 Oct & {$[7,63]$} \\
\hline \multicolumn{3}{|l|}{ Relative abundance } \\
\hline During this period & $100 \%$ & Reference value \\
\hline During the rest of the year & $0 \%$ & Expert opinion \\
\hline
\end{tabular}

statistical analyses were performed. The source code is available upon request.

\subsubsection{Sensitivity analysis}

A systematic univariate sensitivity analysis was conducted to study the effects of parameter variations on the estimated values of the juvenile and adult bite relative risk $(R R)$, and of site-specific vector-host ratios $\left(K_{x}\right)$. For each host and vector parameter (Tabs. I and II), two alternative values were tested (dates: \pm 1 week, durations: \pm 1 day, proportions: $\pm 5 \%$ ), the calibration process resulting in two different estimates of $R R$ and $K_{x}$. The dataset thus obtained was analyzed using a generalized linear model for each of the four estimated parameters $\left(R R\right.$ and the three site-specific $\left.K_{x}\right)$. The independent variables were the variations of the estimates (taking as a reference the results obtained with the default parameter set) and the dependent variables were the host and vector parameters. The generalised linear models were finally used to predict the effect of positive variations of host and vector parameters (dates: +1 week, durations: +1 day, proportions: $+5 \%$ ) on the estimated values of $R R$ and $K_{x}$, and to rank the parameters according to these effects.

\subsection{Exploitation}

\subsubsection{Epidemiological cycle and $W N V$ circulation pattern}

Predicted annual dynamics of the epidemiological system at the equilibrium state were studied using two variables: the proportion of viraemic birds in each of the five modelled populations, and the proportion of infectious vectors in each of the three modelled areas. We then focussed on long distance migrants to quantify WNV flows between Africa and Europe. For this population, we compared the proportion of viraemic birds at two key periods of the annual cycle: the prenuptial migration and the post-nuptial migration. Computing the ratio of the first proportion to the second allowed us to quantify the global direction of WNV flows (from Africa to Europe if the ratio is $>1$, or from Europe to Africa if the ratio is $<1$ ).

We then computed annual cumulated incidence rates of infection to evaluate the relative importance of each population for global WNV circulation, the references being the wet African area populations (resident birds and vectors). 
Table III. Comparison of the predicted values with seroprevalence data observed in African and European wild birds (used for model calibration), incidence data observed in African sentinel chickens and annual infection incidence estimated in African and European horses (used to compute bite relative risk in incidental hosts).

\begin{tabular}{lcccccc}
\hline Animals & Date & Pop. $^{\mathrm{d}}$ & \multicolumn{3}{c}{ Observed or estimated data } & \multirow{2}{*}{ Predicted data } \\
\cline { 4 - 5 } & & & Data $^{\mathrm{e}}$ & Rates $\left(95 \% \mathrm{CI}^{\mathrm{f}}\right)$ & References & \\
\hline Wild birds & & & & & \\
Wet African area & $15 \mathrm{Nov}$ & $\mathrm{R}$ & $6 / 51$ & $0.12(0.04-0.24)$ & {$[15]$} & 0.10 \\
& & $\mathrm{M}$ & $6 / 201$ & $0.03(0.01-0.06)$ & {$[15]$} & 0.05 \\
Dry African area & $1 \mathrm{Oct}$ & $\mathrm{R}+\mathrm{L}$ & $11 / 152$ & $0.07(0.04-0.13)$ & {$[15]$} & 0.07 \\
European area & $15 \mathrm{Apr}$ & $\mathrm{R}$ & $4 / 271$ & $0.01(0.00-0.04)$ & {$[46]$} & 0.01 \\
& & $\mathrm{M}$ & $18 / 240$ & $0.07(0.04-0.12)$ & {$[46]$} & 0.07 \\
Sentinel chicken & & & & & & \\
Dry African area & & & & $0.14(0.07-0.29)$ & {$[13]$} & 0.14 \\
Horses & & & & $0.21(0.20-0.22)$ & {$[14]$} & 0.24 \\
Wet African area & & & & $0.19(0.18-0.21)$ & {$[12]$} & 0.22 \\
Dry African area & & & & $0.04(0.03-0.04)$ & {$[23]$} & 0.03 \\
European area & & & & \\
\hline
\end{tabular}

${ }^{a}$ Observed seroprevalence in Djoud'j National park (Senegal, wet African area), Ferlo area (Senegal, dry African area), and Seville area (Spain, European area).

${ }^{\mathrm{b}}$ Observed incidence rate in Ferlo area (Senegal, dry African area).

${ }^{c}$ Annual incidence rates estimated from age-specific seroprevalence data collected in Senegal river valley (Senegal, wet African area), Ferlo area (Senegal, dry African area), and Var area (France, European area).

${ }^{\mathrm{d}}$ Pop.: population, R: residents, M: long distance migrants, and L: local migrants.

${ }^{\mathrm{e}}$ Number positive and number tested.

${ }^{\mathrm{f}}$ Confidence interval.

The three modelled areas are linked by migratory bird populations that may be infected either on their breeding grounds or on their wintering grounds. To evaluate the respective importance of both infection places, we computed for each migrant population the proportion of infections occurring when birds are on their breeding grounds (the Southern European area for the long distance migrants and the dry African area for the local migrants).

\subsubsection{Computation of bite relative risks in incidental hosts}

Once calibrated, the model was used to compute the bite relative risks for incidental hosts using incidence data [12-14, 23]. For horses, data were collected in a wet African area (Senegal River valley, Senegal) [14], a dry African area (Ferlo, Senegal) [12], and a European area (Var, France) [23]. For each of the three studies, the age of the animals allowed us to compute an annual incidence rate of WNV infection from age-specific seroprevalence rates, as described in [11] (Tab. III). Using these annual rates, the bite relative risk for horses was computed separately for each of the three modelled areas (using Eq. 17, on line Supplementary data available at www.vetres.org). Considering the bite relative risk is independent of the area, estimated value was the average of these three area-specific values. This value was used to compute the predicted annual dynamics of infection rates in horses living in each of the three modelled areas. Bite relative risk was estimated similarly for the sentinel chicken using data from a dry African area (Ferlo, Senegal) [13] (Tab. III).

\section{RESULTS}

\subsection{Parameter estimation}

\subsubsection{Calibration results}

The estimated value of the bite relative risk for flying juvenile and adult birds $(R R)$ was $0.32(95 \%$ confidence interval $(\mathrm{CI})$ : 


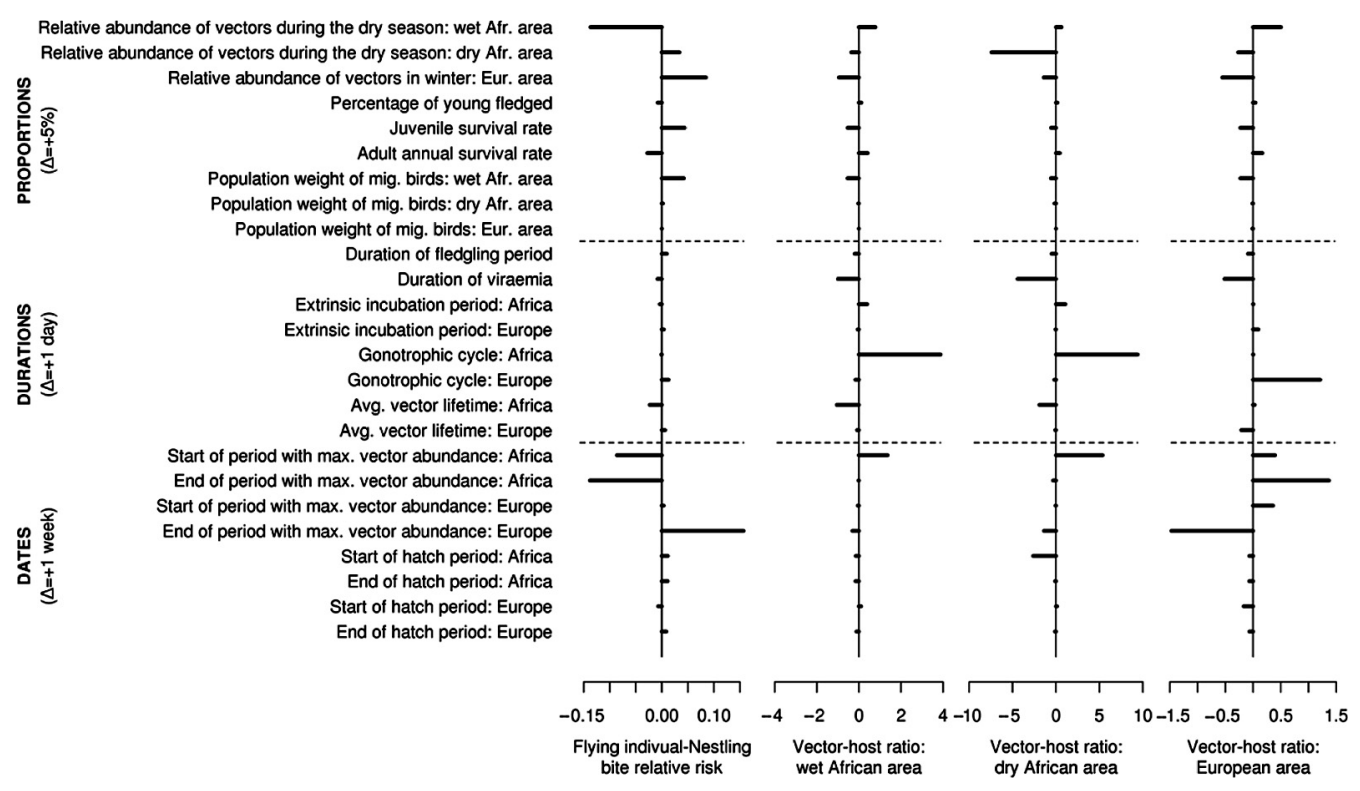

Figure 2. Effect of parameter variations on the estimated values of the bite relative risk for adults and flying juveniles (ref.: nestlings) and of the site-specific vector-host ratios.

0.05-1.92), indicating a predicted bite risk 3 times higher in nestlings than in flying individuals. The estimated vector-host ratio was higher for the dry African area (14.1, 95\% CI: 7.526.5) than for the wet African area (5.8, 95\% CI: 1.5-22.1). For the European area, the estimated vector-host ratio $(2.6,95 \% \mathrm{CI}$ : $0.8-8.9)$ was approximately half that of the wet African area. Using these estimated parameters, predicted seroprevalence rates in bird populations appeared close to the data used for model calibration (Tab. III).

\subsubsection{Sensitivity analysis}

Sensitivity analysis results are summarized in a tornado chart (Fig. 2). The most influential parameter among date-valued parameters was the end of the vector activity period. In the European area, when this period ended later, WNV circulation lasted longer, leading to a lower estimate of the vector-host ratio. Moreover, long distance migrants arrived later on their wintering grounds and were thus less exposed to WNV circulation in the wet African area. This led to a higher estimate of $R R$. Oppositely, when the rainy season ended later in Africa, long distance migrants arrived on their wintering grounds before the end of this maximal vector activity period. This led to a lower estimate of $R R$, and to a higher estimate of the vector-host ratio in the European area. Most of the duration-valued parameters had little effect on the $R R$ estimate, except for the gonotrophic cycle. An increase of the gonotrophic cycle duration led to an increase of the vectorhost ratio estimate in the corresponding area, since the proportion of vectors that bite a host at a given day was lower. Finally, among the proportion-valued parameters, the most influential was the relative abundance of vectors during the dry season in the wet African area. Indeed, in this case, WNV circulation was increased in the wet African area, as was the exposure of migrant populations on their wintering grounds. This led to a decrease of $R R$ estimate, to compensate for this higher exposure during the dry season. 

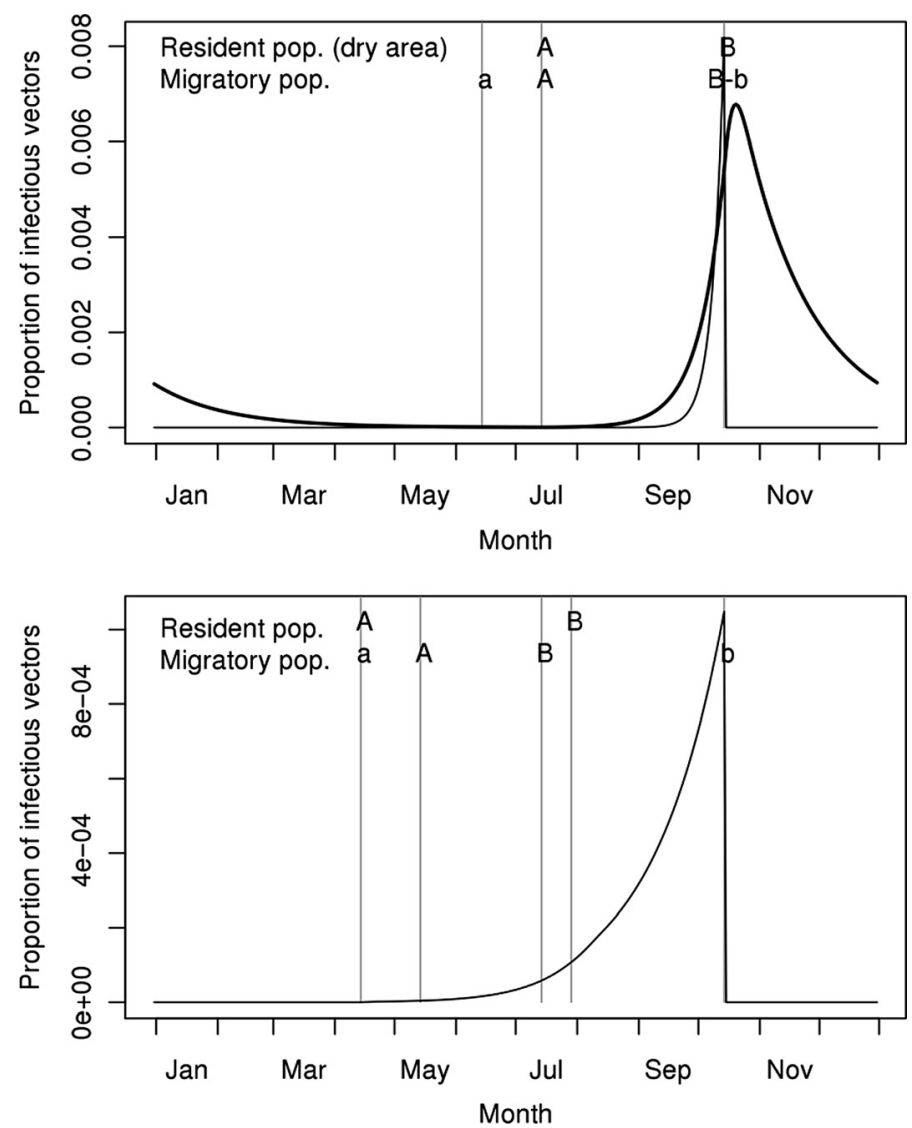

Figure 3. Predicted annual variations of the proportion of infectious vectors in the wet African area (top, thick line), in the dry African area (top, thin line), and in the European area (bottom, thin line). A-B: Hatching periods for the bird populations living in Africa (top, not indicated for the resident population of the wet area for which reproduction is not seasonal) and Europe (bottom). $a-b$ : Presence of the migratory populations on their breeding sites in Africa (top) and in Europe (bottom).

\subsection{Epidemiological cycle and WNV circulation pattern}

\subsubsection{Predicted annual dynamics and WNV flows between Africa and Europe}

The overall proportion of infectious vectors was predicted to be one log lower in Europe than in Africa (Fig. 3), but remained low for the three populations, with maximal values of $1 \%$ for the African areas and $0.1 \%$ for the European area. In the African areas (Fig. 3, top), the predicted proportion of infectious vectors increased exponentially during the rainy season. During the dry season, the base vector activity level allowed a low WNV circulation level in the wet area only. In the European area, the predicted proportion of infectious vectors increased exponentially until the end of the vector activity period (Fig. 3, bottom).

As for vectors, the magnitude of the proportion of viraemic birds was predicted to be approximately 10 times lower in Europe than in Africa. Whatever the population, this proportion 

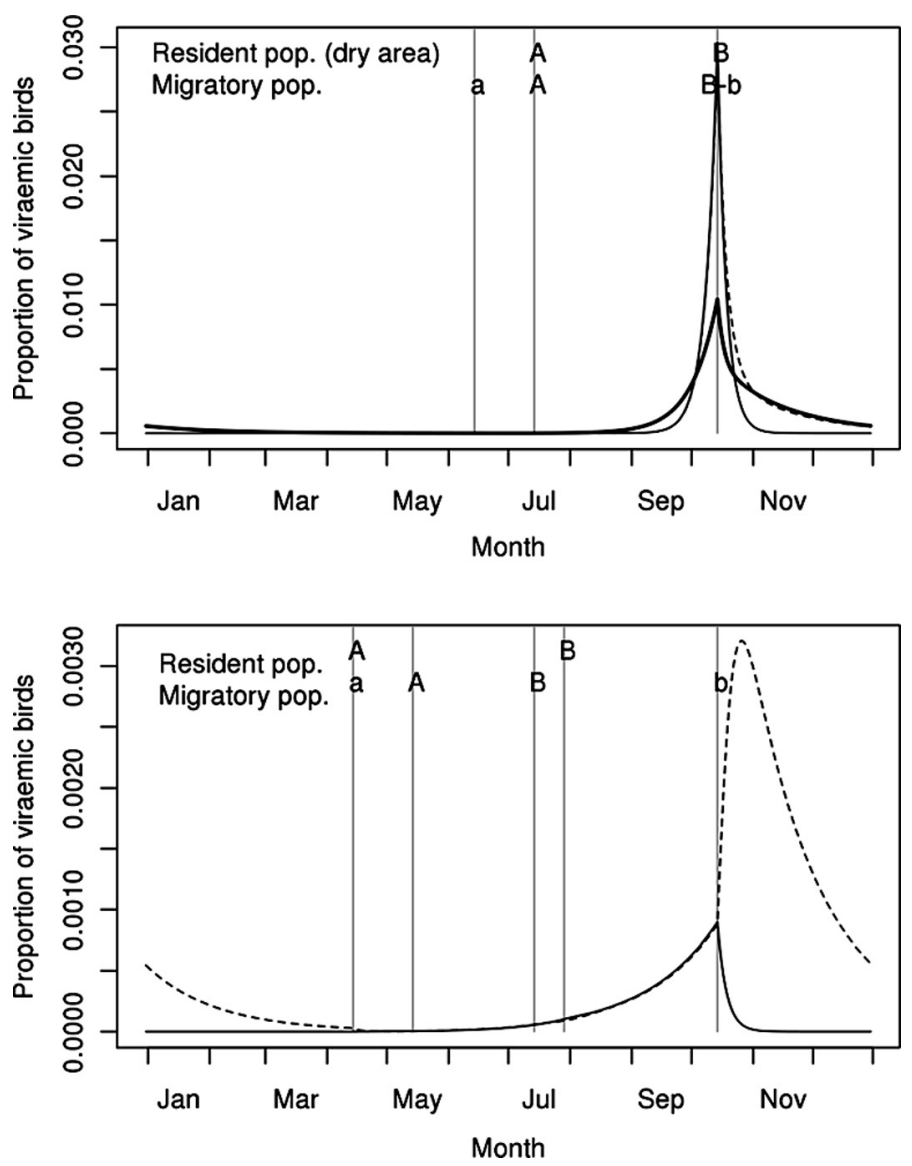

Figure 4. Predicted annual variations of the proportion of viraemic birds in the resident populations of Africa (top, thick line: wet area, thin line: dry area) and Europe (bottom, thin line), and in the migratory populations (dashed lines, top: short distance African migratory population, bottom: long distance migratory population). A-B: Hatching periods for the bird populations living in Africa (top, not indicated for the resident population of the wet area for which reproduction is not seasonal) and Europe (bottom). a-b: Presence of the migratory populations on their breeding sites in Africa (top) and in Europe (bottom).

remained low throughout the year, with a maximal value of $3 \%$ for short distance African migrants at the end of the rainy season. In resident African populations as well as in local migrants, the predicted proportion of viraemic birds peaked at the end of the rainy season, the peak being sharper in the dry area residents and in the short distance migrants (Fig. 4, top). In resident birds of the European area, the predicted proportion of viraemic individuals increased until the end of the vector activity period (Fig. 4, bottom, thin line). In long distance migrants, the predicted infection dynamic was parallel to that of resident European birds during the breeding season, but the main peak occurred after the post-nuptial migration due to the exposure of birds to WNV circulation in the wet African area (Fig. 4, bottom, dashed line).

In migrant populations, the predicted proportion of viraemic birds upon arrival at the breeding site was low: approximately one for $10^{5}$ birds in short and long distance migrants. 

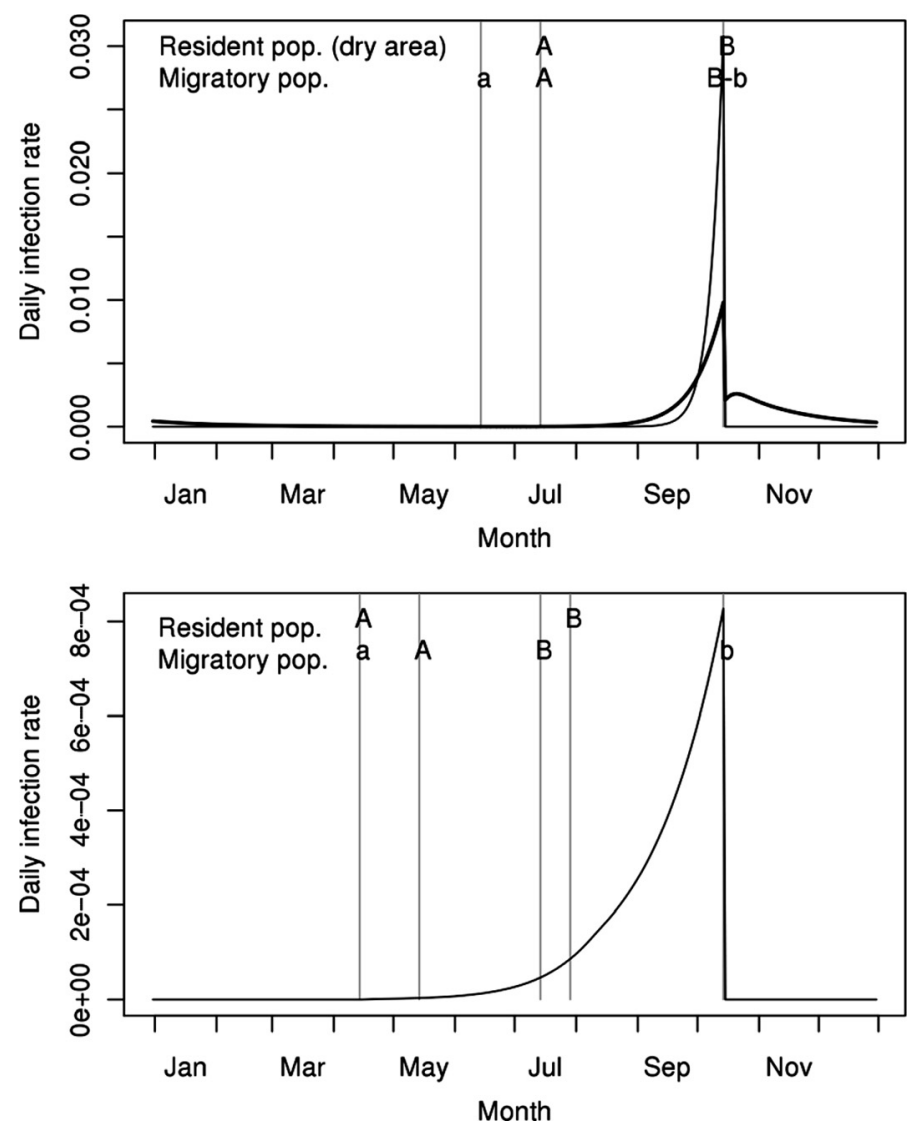

Figure 5. Predicted annual variations of the daily infection rate for horses living in the wet African area (top, thick line), in the dry African area (top, thin line), and in the European area (bottom, thin line). A-B: Hatching periods for the bird populations living in Africa (top, not indicated for the resident population of the wet area for which reproduction is not seasonal) and Europe (bottom). a-b: Presence of the migratory populations on their breeding sites in Africa (top) and in Europe (bottom).

Furthermore, for long distance migrants, the proportion of viraemic birds at post-nuptial migration was 30 times higher than that predicted at prenuptial migration. The direction of the WNV flow was thus clearly from Europe to Africa, the post-nuptial migration being the support of this flow, as well as the support of a massive flow of susceptible birds, born in Europe, to the wet African area. However, none of these flows appeared essential to the overall WNV circulation. Removing the long distance migrant population from the epidemiological system did not significantly affect WNV circu- lation within Africa (virus ultimately disappeared from the European area only).

Finally, the sensitivity analysis showed that the shape of the yearly limit cycle (illustrated by Figs. 3 and 4) was not changed by variations of parameters. In particular, it was the case for the vector activity level during winter in the European area (relative abundance of 5\%,10\% and $20 \%$ instead of $0 \%$ ). Indeed, setting this vector activity level to $20 \%$ (as in the wet African area during the dry season) resulted in a higher estimate of $R R$, and to lower estimates of the three vector-host ratios (Fig. 2). The limit cycle 
resulting from the calibration process showed an increased virus circulation level in resident European birds. However, this increase remained limited: at prenuptial migration, the predicted proportion of viraemic birds was one $\log$ lower in European residents than in residents of the wet African area. Furthermore, removing the long distance migrants from the epidemiological system ultimately led to a disappearance of WNV from the European area. Thus, even when the vector activity during the winter in Europe was strongly increased, the calibration process resulted in an annual cycle without true endemic circulation in Europe, WNV introductions by long distance migrants remaining necessary to virus circulation in this area.

\subsubsection{Relative importance of bird populations in WNV circulation}

The predicted annual cumulated incidence of vector infections was 2.6 times higher in the dry African area than in the wet African area (reference population). For the European area, it was 17 times lower (ratio: 0.06). In bird populations, the annual cumulated incidence of infections was predicted to be similar in residents of the wet African area (reference population) and in short distance migrants (ratio: 1.1). Lower ratios were obtained for the three other populations: 0.8 for residents of the dry African area, 0.4 for long distance migrants, and 0.1 for the residents of the European area. In long distance migrants, $79 \%$ of the infections occurred on the wintering site (wet African area) and $21 \%$ on the European breeding site. In contrast, for short distance migrants, most of the contaminations occurred on the breeding site $(71 \%)$.

\subsection{Incidental hosts}

For horses, the bite relative risks estimated separately for the three modelled areas were 3.5 for the wet African area, 3.8 for the dry African area, and 5.3 for the European area. Using the average value of 4.2 , predicted yearly incidence rates obtained for the three modelled areas were close to the values estimated from seroprevalence data (Tab. III). For sentinel chickens, estimated bite relative risk was slightly lower than that obtained for horses: 2.7. In horses, the predicted annual cycle of the daily infection rate showed marked variations (Fig. 5). In Africa, the infection rate peaked at the end of the rainy season, the maximal value being higher in the dry area than in the wet area. In Europe, the predicted peak of infection rate was approximately two logs lower, but started earlier.

\section{DISCUSSION}

Statistical and mathematical models have been elaborated to link WNF incidence with temperature data [73, 77] and to simulate WNV circulation in epidemiological systems $[8,20,45,65,75]$. These studies aimed to quantify the basic reproduction number R0 and the effect of control measures on its value. In all of these studies, the authors addressed the North American context. In this study, we propose a metapopulation model for WNV circulation between Europe and Africa. The bird populations represented passerines, which are generally considered as playing a major role in WNV circulation [27, 43]. The survival rates were assumed identical in the populations modelled as were the time periods before nestlings leave the nest. However, the reproduction pattern varied according to populations, ranging from a permanent to a seasonal reproduction. Parameters were fixed based on literature data save for the base activity level of vectors in the wet African area which were fixed by entomologists based on their prior experience and knowledge. Key parameters relating to the transmission of infection were calibrated using relevant published data on anti-WNV seroprevalence in African and European bird populations, and in populations visiting both continents during their annual life cycle. The sensitivity analysis allowed identifying the parameters that had the greatest influence on estimated values of $R R$ and site-specific vector-host ratios.

The predicted limit cycle appeared consistent with independent data collected from wild birds, vectors, and horses in various countries. In wild birds, the predicted seroprevalence rate 
at the arrival of spring migrations in Europe (1\% for European resident birds, $7 \%$ for long distance migrants) is close to that obtained in Moravia (Czech Republic) (global rate of $5.6 \%$ for resident and migratory birds) [35]. It is also close to the seroprevalence rate obtained at the same period in Camargue, Southern France: $0.8 \%$ in resident birds and $7.6 \%$ in long distance migrants [37]. In vectors, the predicted proportion of infected mosquitoes in Europe (maximal value: 1/1 000) is also comparable with minimal infection rates obtained in Portugal (Cx. univittatus and Cx. pipiens: 2.8/1 000) [26], Romania (Cx. pipiens: 0.19/1 000) [67], and Russia (Cx. pipiens: 0.79/1 000, Cx. modestus: $2.72 / 1000)$ [29]. In incidental hosts, the model allowed the reproduction of independent serological data from Europe and Africa. The model predicts that the infection rate of European horses peaks from mid-August to midOctober, a period when equine clinical cases were observed in past epidemics in France [49, 56], Italy [4], Russia [61, 62], Romania $[10,72]$ and Israël [74]. The predicted yearly incidence rate $(3 \%)$ is also coherent with the proportion of IgM-positive horses reported in France: $182 / 5107(3.5 \%)$ in 2000 [22] and 23/906 (2.5\%) in 2003 [23]. In France, the follow-up of sentinel horses by Bicout et al. (cited by [44]) in 2001 and 2002 showed seroconversion rates of $4.7 \%$ and $1.4 \%$, respectively. In Spain (2007), the seroconversion rate obtained in a similar study was null $(N=64,95 \%$ $\mathrm{CI}=0-5.6 \%$ ) [2]. These field results are coherent with the predicted incidence rate for European horses. Regarding sentinel chickens, the predicted incidence rate is different from what was recently observed in the Italian Alps (90\%) [66]. However, as suggested by the authors of that study, this very high incidence rate may be explained by a direct, chicken to chicken transmission. This transmission route was not included in our model. In the study used to estimate the chicken bite relative risk [13], the existence of such a route could not be ruled out: if it does exist, the chicken bite relative risk would have been overestimated.

The epidemiological situation obtained after model calibration is a situation in which WNV primarily circulates in the wet African area and is introduced by migratory birds into the dry African area and the European area. The proportion of viraemic birds arriving on the breeding grounds at the time of prenuptial migration is predicted to be low (one for $10^{5}$ birds). However, the Palearctic-African bird migration system comprises nearly 4 billion songbirds [52]. Therefore, even such a low proportion could allow regular introductions of WNV from Africa to Europe. Combined with the predicted amplification of WNV circulation during the hatching period in Europe, this low proportion results in a net WNV flow clearly directed from Europe towards Africa. However, this flow is not necessary to the predicted WNV circulation pattern: only the suppression of the resident bird or vector population of the wet African area interrupts the overall WNV circulation. The estimate of the relative bite risk in flying individuals (adults and juveniles) versus nestlings was $<1$, suggesting an increased WNV circulation during the hatching period. The results of the sensitivity analysis suggest this result is robust, since $R R$ always remained $<0.50$ in the tested situations. This result was also in agreement with field studies [15, 32], although opposite results were recently obtained in the USA [47]. The higher risk for hatchings could be explained by the fact that (i) nestlings are immobile and are not protected by feathers which could make them more attractive to vectors than adult and mobile birds; (ii) their immunological system is immature, viremia being consequently longer as demonstrated in house sparrows and St. Louis encephalitis virus [48]. When confirmed, this hypothesis would imply a predominant WNV circulation on the breeding sites and during the breeding periods. The presence of bird species with an all year round reproduction cycle would thus be a factor favouring WN endemicity in the West African areas in addition to the permanent activity of vectors. Indeed, in the European area where the resident bird population has a seasonal reproduction pattern, the sensitivity analysis showed that even with a year-round vector activity, the calibration process resulted in a limit cycle without true endemic WNV circulation (i.e. maintained even without virus introduction by long distance migrants). Estimates 
of vector-host ratios were consistent with the ecological characteristics of modelled areas, the values in the African areas being more than twice higher than those in the European area. The higher value obtained for the dry African area was consistent with an intense WNV circulation during the rainy season.

This model allows the reproduction of observed patterns in birds, horses, and vectors without including any persistence mechanism. However, the existence of mechanisms such as overwintering and vertical transmission in vectors [21], direct bird to bird transmission [33], and persistent infection in birds [43] cannot be ruled out. Simplifying assumptions were also made in our model. Mortality induced by WNV was not considered since, usually, it is assumed to be negligible in Southern Europe and the Mediterranean basin [60]. Moreover, in a context of epidemiological equilibrium, such mortality (if it were significant) would be included in the overall mortality. The appearance of a more virulent strain could nevertheless induce changes in WNV dynamics and increase virus transmission, as was suggested by a recent modelling study that addressed the North American context [28]. Passive immunity to WNV was neglected as transmission of maternal antibodies appears limited in passerines [59]. The duration of migrations was also not explicitly represented. Most of the long distance migrants use an intermittent flight strategy during migrations: they fly at night and rest or feed during the day. A recent study [68] has shown that they also adopt this strategy while crossing the Sahara. Thus, migrations should not be considered as long non-stop flight during which WNV cannot circulate, but rather as a succession of short night flights and of diurnal stops, during which WNV can circulate if vectors are present. Therefore, instead of including an intermediate state for migration periods, we chose to consider a situation in which, at a given point of its migration route and between two stops, a migrant population switches from African conditions to European conditions (in terms of vector abundance).

Lastly, the proposed model does not explain the large preponderance of lineage I in Europe.
Besides the existence of overwintering mechanisms allowing an endemic WNV transmission in some European areas, there could be two possible explanations: (i) both lineages I and II are introduced equally in Europe but European vectors either are not or are poorly competent to transmit lineage II; (ii) lineage I is more prevalent in Africa than lineage II and the probability of introduction of lineage I is higher than for lineage II.

In conclusion, the proposed model is based upon a simplified hypothesis about global WNV circulation in Southern Europe and the Mediterranean basin. This model satisfactorily reproduces incidence and prevalence data from several countries and continents that were collected in wild birds, vectors, and incidental hosts. Therefore, it does not seem necessary to make additional assumptions about mechanisms allowing a permanent viral circulation in Europe to account for global WNV circulation even if the existence of such mechanisms cannot be ruled out.

Acknowledgements. We thank Elsa Jourdain, Bernard Mondet and Thomas Balenghien for their help in interpreting bird and vector data. This publication was partially funded by the GOCE-2003-010284 EDEN, and ARBOZOONET funding (EU grant agreement 211757). This publication is catalogued by the EDEN Steering Committee as EDEN0187 (www.edenfp6project.net). The contents of this publication are the sole responsibility of the authors and do not necessarily reflect the views of the European Commission.

\section{REFERENCES}

[1] Abbassy M.M., Osman M., Marzouk A.S., West Nile virus (Flaviviridae: Flavivirus) in experimentally infected Argas ticks (Acari: Argasidae), Am. J. Trop. Med. Hyg. (1993) 48:726-737.

[2] Alba A., Busquets N., Allepuz A., Abad F.X., Serrano E., Casal J., West Nile virus surveillance in Catalonia, 2007, Epidémiol. Santé Anim. (2008) 54:80-89.

[3] Austin R.J., Whiting T.L., Anderson R.A., Drebot M.A., An outbreak of West Nile virus-associated disease in domestic geese (Anser anser domesticus) upon initial introduction to a geographic region, with evidence of bird to bird transmission, Can. Vet. J. (2004) 45:117-123. 
[4] Autorino G.L., Battisti A., Deubel V., Ferrari G., Forletta R., Giovannini A., et al., West Nile virus epidemic in horses, Tuscany region, Italy, Emerg. Infect. Dis. (2002) 8:1372-1378.

[5] Bakonyi T., Ivanics E., Erdelyi K., Ursu K., Ferenczi E., Weissenbock H., Nowotny N., Lineage 1 and 2 strains of encephalitic West Nile virus, central Europe, Emerg. Infect. Dis. (2006) 12:618-623.

[6] Balança G., Gaidet N., Savini G., Vollot B., Foucart A., Reiter P., et al., Low West Nile virus circulation in wild birds in an area of recurring outbreaks in Southern France, Vector Borne Zoonotic Dis. (2009) 9:737-741.

[7] Balenghien T., Fouque F., Sabatier P., Bicout D.J., Horse, bird and human-seeking behaviour and seasonanl abundance of mosquitoes in a West Nile focus of southern France, J. Med. Entomol. (2006) 43:936-946.

[8] Bowman C., Gumel A.B., van den Driessche P., $\mathrm{Wu}$ J., Zhu H., A mathematical model for assessing control strategies against West Nile virus, Bull. Math. Biol. (2005) 67:1107-1133.

[9] Bunning M.L., Bowen R.A., Cropp B., Sullivan K., Davis B., Komar N., et al., Experimental infection of horses with West Nile virus and their potential to infect mosquitoes and serve as amplifying hosts, Ann. N.Y. Acad. Sci. (2001) 951:338-339.

[10] Cernescu C., Nedelcu N.I., Tardei G., Ruta S., Tsai T.F., Continued transmission of West Nile virus to humans in southeastern Romania, 1997-1998, J. Infect. Dis. (2000) 181:710-712.

[11] Chevalier V., Lancelot R., Thiongane Y., Sall B., Diaite A., Mondet B., Rift valley fever in small ruminants, Senegal, 2003, Emerg. Infect. Dis. (2005) 11:1693-1700.

[12] Chevalier V., Lancelot R., Diaite A., Mondet B., Sall B., De Lamballerie X., Serological assessment of West Nile fever virus activity in the pastoral system of Ferlo, Senegal, Ann. N.Y. Acad. Sci. (2006) 1081:216-225.

[13] Chevalier V., Lancelot R., Diaite A., Mondet B., De Lamballerie X., Use of sentinel chickens to study the transmission dynamics of West Nile virus in a sahelian ecosystem, Epidemiol. Infect. (2008) 136: $525-528$.

[14] Chevalier V., Dupressoir A., Tran A., Diop Gottland C., Diallo M., et al., Environmental risk factors of West Nile infection of horses in the Senegal river basin, Epidemiol. Infect. (2010) (in press).

[15] Chevalier V., Reynaud P., Lefrancois T., Durand B., Baillon F., Balanca G., et al., Predicting West Nile virus seroprevalence in wild birds in Senegal, Vector Borne Zoonotic Dis. (2009) 9:589-596.

[16] Cornel A.J., Jupp P.G., Blackburn N.K., Environmental temperature on the vector competence of Culex univittatus (Diptera: Culicidae) for West Nile virus, J. Med. Entomol. (1993) 30:449-456.

[17] Cramp S., The birds of the Western Palearctic, Vol. 6, Oxford University Press, 1992.

[18] Cramp S., The birds of the Western Palearctic, Vol. 7, Oxford University Press, 1993.

[19] Cramp S., The birds of the Western Palearctic, Vol. 8, Oxford University Press, 1994.

[20] Cruz-Pacheco G., Esteva L., Montano-Hirose J.A., Vargas C., Modelling the dynamics of West Nile virus, Bull. Math. Biol. (2005) 67:1157-1172.

[21] Dohm D., O'Guinn M., Turell M.J., Effect of environmental temperature on the ability of Culex pipiens (Diptera: Culicidae) to transmit West Nile virus, J. Med. Entomol. (2002) 39:221-225.

[22] Durand B., Chevalier V., Pouillot R., Labie J., Marendat I., Murgue B., et al., West Nile virus outbreak in horses, Southern France, 2000: results of a serosurvey, Emerg. Infect. Dis. (2002) 8:777-782.

[23] Durand B., Dauphin G., Zeller H., Labie J., Schuffenecker I., Murri S., et al., Serosurvey for West Nile virus in horses in Southern France, Vet. Rec. (2005) 157:711-713.

[24] Erdelyi K., Ursu K., Ferenczi E., Szeredi L., Ratz F., Skare J., Bakonyi T., Clinical and pathologic features of lineage 2 West Nile virus infections in birds of prey in Hungary, Vector Borne Zoonotic Dis. (2007) 7:181-188.

[25] Erickson S., Platt K., Tucker B., Evans R., Tiawsirisup S., Rowley W., The potential of Aedes triseriatus (Diptera: Culicidae) as an enzootic vector of West Nile virus, J. Med. Entomol. (2006) 43:966-970.

[26] Esteves A., Almeida A.P., Galao R.P., Parreira R., Piedade J., Rodrigues J.C., et al., West Nile virus in Southern Portugal, 2004, Vector Borne Zoonotic Dis. (2005) 5:410-413.

[27] Ezenwa V.O., Godsey M.S., King R.J., Guptill S.C., Avian diversity and West Nile virus: testing associations between biodiversity and infectious disease risk, Proc. Biol. Sci. (2006) 273:109-117.

[28] Foppa I.M., Spielman A., Does reservoir host mortality enhance transmission of West Nile virus?, Theor. Biol. Med. Model. (2007) 4:17.

[29] Fyodorova M.V., Savage H.M., Lopatina J.V., Bulgakova T.A., Ivanitsky A.V., Platonova O.V., 
Platonov A.E., Evaluation of potential West Nile virus vectors in Volgograd region, Russia, 2003 (Diptera: Culicidae): species composition, bloodmeal host utilization, and virus infection rates of mosquitoes, J. Med. Entomol. (2006) 43:552-563.

[30] Gad A., el Said S., Soliman B., Hassan A., Shoukry A., Distribution and bionomics of Egyptian Culex univittatus (Theobald), J. Egypt Soc. Parasitol. (1987) 17:17-31.

[31] Gad A., Feinsod F., Soliman B., Said S., Survival estimates for adult Culex pipiens in the Nile Delta, Acta Trop. (1989) 46:173-179.

[32] Hamer G.L., Walker E.D., Brawn J.D., Loss S.R., Ruiz M.O., Goldberg T.L., et al., Rapid amplification of West Nile virus: the role of hatch-year birds, Vector Borne Zoonotic Dis. (2008) 8:57-67.

[33] Hartemink N.A., Davis S.A., Reiter P., Hubalek Z., Heesterbeek J.A., Importance of bird-to-bird transmission for the establishment of West Nile virus, Vector Borne Zoonotic Dis. (2007) 7:575-584.

[34] Hubalek Z., Halouzka J., West Nile fever - a reemerging mosquito-borne viral disease in Europe, Emerg. Infect. Dis. (1999) 5:643-650.

[35] Hubalek Z., Halouzka J., Juricova Z., Sikutova S., Rudolf I., Honza M., et al., Serologic survey of birds for West Nile flavivirus in southern Moravia (Czech Republic), Vector Borne Zoonotic Dis. (2008) 8: 659-666.

[36] Jourdain E., Gauthier-Clerc M., Sabatier P., Grege O., Greenland T., Leblond A., et al., Magpies as hosts for West Nile virus, Southern France, Emerg. Infect. Dis. (2008) 14:158-160.

[37] Jourdain E., Zeller H.G., Sabatier P., Murri S., Kayser Y., Greenland T., et al., Prevalence of West Nile virus neutralizing antibodies in wild birds from the Camargue area, Southern France, J. Wildl. Dis. (2008) 44:766-771.

[38] Jupp P., The susceptibility of four South African species of Culex to West Nile and Sindbis viruses by two different infecting methods, Mosq. News (1976) 36:166-173.

[39] Jupp P.G., McIntosh B.M., Quantitative experiments on the vector capability of Culex (Culex) univittatus Theobald with West Nile and Sindbis viruses, J. Med. Entomol. (1970) 7:371-373.

[40] Jupp P.G., Laboratory studies on the transmission of West Nile virus by Culex (Culex) univittatus Theobald; factors influencing the transmission rate, J. Med. Entomol. (1974) 11:455-458.

[41] Juricova Z., Pinowski J., Literak I., Hahm K.H., Romanowski J., Antibodies to alphavirus, flavivirus, and bunyavirus arboviruses in house sparrows (Passer domesticus) and tree sparrows (P. montanus) in Poland, Avian Dis. (1998) 42:182-185.

[42] Kecsemeti S., Bajmocy E., Bacsadi A., Kiss I., Bakoni T., Encephalitis due to West Nile virus in a sheep, Vet. Rec. (2007) 161:568-569.

[43] Komar N., Langevin S., Hinten S., Nemeth N., Edwards E., Hettler D., et al., Experimental infection of North American birds with the New York 1999 strain of West Nile virus, Emerg. Infect. Dis. (2003) 9:311-322.

[44] Lecollinet S., Lefrançois T., Durand B., Leblond A., Dauphin G., de Goer J., Zientara S., Surveillance de l'infection équine à virus West-Nile en France: 2000-2007, Epidémiol. Santé Anim. (2008) 54:69-80.

[45] Lewis M., Renclawowicz J., van den Driessche P., Traveling waves and spread rates for a West Nile virus model, Bull. Math. Biol. (2006) 68:3-23.

[46] Lopez G., Jimenez-Clavero M.A., Tejedor C.G., Soriguer R., Figuerola J., Prevalence of West Nile virus neutralizing antibodies in Spain is related to the behavior of migratory birds, Vector Borne Zoonotic Dis. (2008) 8:615-621.

[47] Loss S.R., Hamer G.L., Goldberg T.L., Ruiz M.O., Kitron U.D., Walker E.D., Brawn J.D., Nestling passerines are not important hosts for amplification of West Nile virus in Chicago, Illinois, Vector Borne Zoonotic Dis. (2009) 9:13-18.

[48] Ludwig G.V., Cook R.S., McLean R.G., Francy D.B., Viremic enhancement due to transovarially acquired antibodies to St. Louis encephalitis virus in birds, J. Wildl. Dis. (1986) 22:326-334.

[49] Mailles A., Dellamonica P., Zeller H., Durand J.P., Zientara S., Gofette R., et al., Human and equine West-Nile virus infections in France, August-September 2003, Eurosurveillance (2003) 7:2312.

[50] Moller A.P., Senescence in relation to latitude and migration in birds, J. Evol. Biol. (2007) 20:750-757.

[51] Mondet B., Diaïté A., Fall A.G., Chevalier V., Relations entre la pluviométrie et le risque de transmission virale par les moustiques : cas du virus de la Rift Valley fever (RVF) dans le Ferlo (Sénégal), Environnement, Risques et Santé (2005) 4:125-129.

[52] Moreau R.E., The Palaearctic-African bird migration systems, Academic Press, London, UK and New York, NY, 1972.

[53] Morel G., Contribution à la synéologie des oiseaux du Sahel sénégalais, Mém. ORSTOM (1968) 179.

[54] Morel G., Morel M., Les oiseaux de Sénégambie, Paris, ORSTOM, 1990. 
[55] Mumcuoglu K.Y., Banet-Noach C., Malkinson M., Shalom U., Galun R., Argasid ticks as possible vectors of West Nile virus in Israel, Vector Borne Zoonotic Dis. (2005) 5:65-71.

[56] Murgue B., Murri S., Zientara S., Durand B., Durand J.P., Zeller H., West Nile outbreak in horses in Southern France, 2000: the return after 35 years, Emerg. Infect. Dis. (2001) 7:692-696.

[57] Murgue B., Zeller H., Deubel V., The ecology and epidemiology of West Nile virus in Africa, Europe and Asia, Curr. Top. Microbiol. Immunol. (2002) 267:195-221.

[58] Nasci R.S., Savage H.M., White D.J., Miller J.R., Cropp B.C., Godsey M.S., et al., West Nile virus in overwintering Culex mosquitoes, New York City, 2000, Emerg. Infect. Dis. (2001) 7:742-744.

[59] Nemeth N.M., Oesterle P.T., Bowen R.A., Passive immunity to West Nile virus provides limited protection in a common passerine species, Am. J. Trop. Med. Hyg. (2008) 79:283-290.

[60] Petersen L.R., Roerigh J.T., West Nile virus: a reemerging global pathogen, Rev. Biomed. (2001) 12: $208-216$.

[61] Platonov A.E., Shipulin G.A., Shipulina O.Y., Tyutyunnik E.N., Frolochkina T.I., Lanciotti R.S., et al., Outbreak of West Nile virus infection, Volgograd Region, Russia, 1999, Emerg. Infect. Dis. (2001) 7:128-132.

[62] Platonov A.E., Fedorova M.V., Karan L.S., Shopenskaya T.A., Platonova O.V., Zhuravlev V.I., Epidemiology of West Nile infection in Volgograd, Russia, in relation to climate change and mosquito (Diptera: Culicidae) bionomics, Parasitol. Res. (2008) 103(Suppl. 1):S45-S53.

[63] Poncon N., Toty C., L'Ambert G., le Goff G., Brengues C., Schaffner F., Fontenille D., Population dynamics of pest mosquitoes and potential malaria and West Nile virus vectors in relation to climatic factors and human activities in the Camargue, France, Med. Vet. Entomol. (2007) 21:350-357.

[64] R Development Core Team, R: A Language and Environment for Statistical Computing. R Foundation for Statistical Computing, Vienna, Austria, ISBN: 3-900051-07-0, 2009.

[65] Rappole J.H., Compton B.W., Leimgruber P., Robertson J., King D.I., Renner S.C., Modeling movement of West Nile virus in the Western hemisphere, Vector Borne Zoonotic Dis. (2006) 6: 128-139.
[66] Rizzoli A., Rosa R., Rosso F., Buckley A., Gould E.A., West Nile virus circulation detected in northern Italy in sentinel chickens, Vector Borne Zoonotic Dis. (2007) 3:411-417.

[67] Savage H.M., Ceianu C., Nicolescu G., Karabatsos N., Lanciotti R., Vladimirescu A., et al., Entomologic and avian investigations of an epidemic of West Nile fever in Romania in 1996, with serologic and molecular characterization of a virus isolate from mosquitoes, Am. J. Trop. Med. Hyg. (1999) 61:600-611.

[68] Schmaljohann H., Liechti F., Bruderer B., Songbird migration across the Sahara: the non-stop hypothesis rejected!, Proc. Biol. Sci. (2007) 274: 735-739.

[69] Summers-Smith J., The sparrows: a study of the genus Passer, A\&C Black Publishers Ltd, 1988, p. 342 .

[70] Tiawsirisup S., Platt K., Evans R., Rowley W., Susceptibility of Ochlerotatus trivittatus (Coq.), Aedes albopictus (Skuse), and Culex pipiens (L.) to West Nile virus infection, Vector Borne Zoonotic Dis. (2004) 4:190-197.

[71] Tsai T.F., Factors in the changing epidemiology of Japanese encephalitis and West Nile fever, in: Saluzzo R.F., Dodet B. (Eds.), Factors in the emergence of arbovirus diseases, Elsevier, Paris, 1997, pp. 179-189.

[72] Tsai T.F., Popovici F., Cernescu C., Campbell G.L., Nedelcu N.I., West Nile encephalitis epidemic in southeastern Romania, Lancet (1998) 352:767-771.

[73] Ward M.P., Epidemic West Nile virus encephalomyelitis: a temperature-dependent, spatial model of disease dynamics, Prev. Vet. Med. (2005) 71:253-264.

[74] Weinberger M., Pitlik S.D., Gandacu D., Lang R., Nassar F., Ben David D., et al., West Nile fever outbreak, Israel, 2000: epidemiologic aspects, Emerg. Infect. Dis. (2001) 7:686-691.

[75] Wonham M.J., de-Camino-Beck T., Lewis M.A., An epidemiological model for West Nile virus: invasion analysis and control applications, Proc. Biol. Sci. (2004) 271:501-507.

[76] Zeller H.G., Schuffenecker I., West Nile virus: an overview of its spread in Europe and the Mediterranean basin in contrast to its spread in the Americas, Eur. J. Clin. Microbiol. Infect. Dis. (2004) 23:147-156.

[77] Zou L., Miller S.N., Schmidtmann E.T., A GIS tool to estimate West Nile virus risk based on a degree-day model, Environ. Monit. Assess. (2007) 129:413-420. 